\title{
Positron Emission Tomography Imaging of Transplant Function
}

\author{
David J. Brooks \\ Medical Research Council Clinical Sciences Centre and Division of Neuroscience, Faculty of Medicine, Imperial College, \\ Hammersmith Hospital, London W12 ONN, United Kingdom
}

\begin{abstract}
Summary: In this article, the role of functional imaging for providing objective evidence that grafts of fetal tissue can survive and form connections in Parkinson's and Huntington's disease patients is reviewed. The dissociation between dopamine storage capacity, clinical improvement, and normalization of brain metabolism in PD is discussed, and possible mechanisms underlying the phenomenon of dyskinesias off medica-
\end{abstract}

tion are presented. It is concluded the positron emission tomography and single photon emission computed tomography can provide valuable ancillary information alongside clinical observations but are not currently appropriate modalities for use as surrogate endpoints. Key Words: Parkinson's disease, Huntington's disease, PET, SPECT, dopamine storage, transplant function.

\section{INTRODUCTION}

Positron emission tomography (PET) allows regional changes in brain metabolism, blood flow, and receptor binding to be detected in vivo and quantitated in Parkinson's disease (PD) and Huntington's disease (HD). Current tomographs have a resolution of 3-4 $\mathrm{mm}$ and so are potentially capable of examining the function of individual implant sites in the striatum. There are two main approaches when using functional imaging to measure the changes in regional cerebral function associated with neurodegenerative disorders and transplantation: 1) resting changes in regional cerebral metabolism, blood flow, and neuroreceptor binding can be studied in the host brain and grafted tissue, and 2) alterations in the levels of regional cerebral blood flow (rCBF) or dopamine release can be monitored while patients perform motor paradigms. In this way, the efficacy of stereotaxically implanted tissue in normalizing regional cerebral metabolism, neurotransmission, and task-induced activation can be determined in movement disorder patients.

Current PET cameras have a reconstructed image resolution of $4-5 \mathrm{~mm}$ and are now able to examine the function of individual brainstem nuclei, Brodmann cortical areas, and tissue implant sites. Their increased sensitivity also enables raw images of tracer uptake to be

Address correspondence and reprint requests to David J. Brooks, Imperial College, Medical Research Council Clinical Sciences Centre and Division of Neuroscience, London W12 ONN, United Kingdom. E-mail: david.brooks@mrc.ac.uk. converted to parametric maps of tracer influx constants $\left(K_{\mathrm{i}}\right)$ or volumes of distribution representing specific binding at a voxel level. These parametric images of $\mathrm{rCBF}$, resting and activated metabolism, or receptor binding can then be interrogated with statistical parametric mapping (SPM) to localize clusters of voxels where change has occurred in patients with PD or HD compared with controls or before and after transplantation. SPM has the advantage over a standard region-of-interest approach that changes in regional brain and graft function may be detected in brain areas that were not sampled a priori. The disadvantage of SPM is the requirement for stereotaxic transformation of three-dimensional data sets with a resultant loss of spatial resolution.

\section{THE PRESYNAPTIC DOPAMINERGIC SYSTEM}

${ }^{18} \mathrm{~F}$-dopa PET was the first in vivo marker of dopamine terminal function to be developed. After its intravenous administration ${ }^{18} \mathrm{~F}$-dopa is taken up by the terminals of dopaminergic projections and stored as ${ }^{18} \mathrm{~F}$-dopamine and its metabolites. ${ }^{1}$ The rate of striatal ${ }^{18} \mathrm{~F}$ accumulation reflects both ${ }^{18} \mathrm{~F}$-dopa transport into striatal dopamine vesicles and its decarboxylation by dopa decarboxylase (DDC). Within the $90 \mathrm{~min}$ of a conventional ${ }^{18} \mathrm{~F}$-dopa PET scan, striatal ${ }^{18} \mathrm{~F}$ uptake can be regarded as essentially unidirectional and so can be represented kinetically by an influx constant, $K_{\mathrm{i}}{ }^{2,3}{ }^{18} \mathrm{~F}$-dopa PET, coupled with SPM, reveals bilateral loss of ${ }^{18} \mathrm{~F}$-dopa uptake in puta- 
men in early hemi-PD patients, dorsal structures being more affected than ventral. ${ }^{4}$ Reductions of motor cortex and posterior cingulate $K_{\mathrm{i}}$ can also be detected. In patients with established bilateral PD, ${ }^{18} \mathrm{~F}$-dopa $K_{\mathrm{i}}$ is reduced in dorsal and ventral caudate and putamen, substantia nigra, and midbrain tegmentum and also in motor, premotor, and prefrontal cortex. Levels of putamen ${ }^{18} \mathrm{~F}$ dopa uptake in PD correlate with clinical disease severity rated off medication, as reflected by the unified Parkinson's disease rating scale (UPDRS). ${ }^{5}$ Whereas ${ }^{18} \mathrm{~F}$-dopa uptake reflects striatal dopamine terminal density, levels of DDC activity are also subject to compensatory regulation when terminal loss occurs, as in PD, and may also be influenced by dopaminergic agents. ${ }^{6}$ Given this, striatal $K_{\mathrm{i}}$ values may well overestimate nigral cell reserves in PD.

Subsequently, PET and single-photon emission computed tomography (SPECT) tracers that bind to dopamine transporters (DAT) on nigrostriatal terminals and monoamine vesicular transporters (VMAT2) have been developed. DAT tracers are in the main tropane-based markers, such as ${ }^{11} \mathrm{C}-\mathrm{CFT},{ }^{11} \mathrm{C}-\mathrm{RTI}-32,{ }^{123} \mathrm{I}-\beta$-CIT, and ${ }^{123}{\mathrm{I}-\mathrm{FP}-\mathrm{CIT}^{7-10}}$, whereas non-tropane-based markers include ${ }^{11} \mathrm{C}$-methylphenidate ${ }^{11}$ and ${ }^{11} \mathrm{C}$-nomifensine. ${ }^{12}$ Uptake of these tracers correlates with PD disability rated off medication but, like DDC, the DAT is potentially subject to compensatory regulation and direct pharmacological effects. ${ }^{13}$ In contrast to ${ }^{18} \mathrm{~F}$-dopa PET, DAT markers are likely to underestimate rather than overestimate nigral cell reserve. The only well established VMAT2 marker is ${ }^{11} \mathrm{C}$-dihydrotetrabenazine (DTBZ) PET. ${ }^{14}$ Striatal uptake of ${ }^{11} \mathrm{C}$-DTBZ correlates with PD UPDRS scores, and it has been suggested that this modality is less sensitive to regulation than DDC or DAT markers and so gives a truer reflection of dopamine terminal density. ${ }^{11}$

\section{THE POSTSYNAPTIC DOPAMINERGIC SYSTEM}

Postsynaptic dopamine receptors broadly fall into two classes: $D_{1}$-type $\left(D_{1}, D_{5}\right)$, which are adenyl cyclase dependent, and $\mathrm{D}_{2}$-type $\left(\mathrm{D}_{2}, \mathrm{D}_{3}, \mathrm{D}_{4}\right)$, which are not. The striatum contains mainly $\mathrm{D}_{1}$ and $\mathrm{D}_{2}$ receptors, and both play a primary role in modulating locomotor function. In untreated PD patients later shown to be responsive to levodopa or apomorphine spiperone-based tracer PET and ${ }^{123}$ I-IBZM, SPECT studies have generally reported normal levels of striatal binding, whereas ${ }^{11} \mathrm{C}$-raclopride PET studies have shown 10-20\% increases in putamen $\mathrm{D}_{2}$ site availability contralateral to the more affected limbs. ${ }^{15-17}$ In long-term medicated PD, spiperone-based tracer PET and ${ }^{123}$ I-IBZM SPECT studies have reported normal and reduced striatal $\mathrm{D}_{2}$ binding in chronically treated PD. ${ }^{11} \mathrm{C}$-raclopride PET has shown that, after several months of exposure to levodopa, initially in- creased putamen ${ }^{11} \mathrm{C}$-raclopride binding in de novo $\mathrm{PD}$ patients normalizes. ${ }^{16,18}$

PET studies with spiperone-based tracers, ${ }^{19}{ }^{11} \mathrm{C}$-raclopride, ${ }^{20}$ and ${ }^{123}$ I-IBZM SPECT ${ }^{21}$ have all shown that striatal $D_{2}$ binding is severely reduced in affected HD patients. A significant loss of striatal $\mathrm{D}_{2}$ binding can also be detected in asymptomatic adults with the HD mutation, ${ }^{22}$ with patients becoming symptomatic after $\sim 30 \%$ loss of striatal dopamine $\mathrm{D}_{2}$ binding.

\section{INDIRECT ASSESSMENT OF DOPAMINE RELEASE}

${ }^{11} \mathrm{C}$-raclopride and ${ }^{123} \mathrm{I}$-IBZM are both benzamide ligands with affinity for the $\mathrm{D} 2$ receptor in the low nanomolar range and so are subject to competitive displacement by endogenous dopamine. ${ }^{23}$ They are also unable to attach to D2 receptors that have been temporarily internalized into the cell soma after binding of endogenous dopamine. ${ }^{24}$ Agents known to increase levels of synaptic DA, such as levodopa ${ }^{25}$ and amphetamine, ${ }^{26}$ result in reduced striatal ${ }^{11} \mathrm{C}$-raclopride and ${ }^{123} \mathrm{I}$-IBZM binding, as does locomotor activity. ${ }^{27}$ In normal subjects, a $0.3 \mathrm{mg} / \mathrm{kg}$ infusion of amphetamine results in a $25 \%$ reduction in striatal ${ }^{11} \mathrm{C}$-raclopride binding, which has been estimated to represent at least a 10-fold increase in synaptic dopamine levels. ${ }^{28}$ In PD patients, infusion of amphetamine results on average in only $40 \%$ of the dopamine release seen in normal subjects. ${ }^{29}$

\section{RESTING METABOLIC AND ACTIVATION STUDIES}

${ }^{15} \mathrm{O}_{2}$ and 18F-2-fluoro-2-deoxy-D-glucose ( ${ }^{18} \mathrm{FDG}$ )PET studies have shown increased levels of resting oxygen and glucose metabolism in the contralateral lentiform nucleus of hemiparkinsonian patients with early disease. ${ }^{30,31}$ PD patients with established bilateral symptoms have normal levels of lentiform metabolism. ${ }^{30,32}$ Covariance analysis, however, reveals an abnormal profile of relatively raised resting lentiform nucleus and lowered frontal metabolism in PD patients with established disease even when absolute values are normal. ${ }^{32}$ The degree of expression of this profile correlates with clinical disease severity. ${ }^{33}$

When normal subjects perform either paced movements of a joystick in freely selected directions, there are associated increases in $\mathrm{rCBF}$ in the contralateral sensorimotor cortex and lentiform nucleus and bilaterally in anterior cingulate, supplementary motor area (SMA), lateral premotor cortex, and dorsolateral prefrontal cortex (DLPFC). ${ }^{34,35}$ PD patients, taken off medication for $12 \mathrm{~h}$, show selectively impaired activation of the contralateral lentiform nucleus and the anterior cingulate, rostral SMA, and dorsal prefrontal cortex when they 
perform this motor task, i.e., impaired activation of those cortical areas that receive their main input from the basal ganglia. Normalization of the pattern of resting glucose metabolism and of activation of the SMA and DLPFC during movement can be restored in PD patients after treatment with dopaminergic agents such as levodopa ${ }^{36}$ and apomorphine ${ }^{37}$ or deep brain stimulation of the internal pallidum ${ }^{38}$ and subthalamus. ${ }^{39}$

With ${ }^{18} \mathrm{FDG}$ and ${ }^{15} \mathrm{O}_{2}$ PET, clinically affected HD patients show severely reduced resting levels of glucose and oxygen metabolism of the caudate and lentiform nuclei. $^{40-42}$ Levels of resting putamen metabolism correlate with locomotor function and caudate metabolism with performance on tests sensitive to frontal lobe function. ${ }^{43,44}$ In early HD, cortical metabolism is preserved but as the disease progresses and dementia becomes prominent it also declines, with the frontal cortex being targeted. ${ }^{45}$ Reduced caudate glucose metabolism has been reported in between $38 \%$ and $75 \%$ of asymptomatic adult HD gene carriers in various series. ${ }^{46-48}$ It has been estimated that at least a $30 \%$ loss of striatal glucose metabolism is required before HD gene carriers become symptomatic.

\section{IMAGING MEASUREMENTS OF PD AND HD PROGRESSION}

PET and SPECT both provide in vivo means of objectively monitoring the progression of neurodegenerative disorders and the functional effects of restorative treatments. An average $7-12 \%$ annual decline in baseline putamen dopaminergic function has been reported in early PD using ${ }^{18}$ F-dopa PET, ${ }^{18}$ F-CFT PET, and ${ }^{123} \mathrm{I}$ $\beta$-CIT SPECT. ${ }^{49-51}$ These studies have estimated a preclinical window of 4-6 years for late onset idiopathic disease. The rate of progression of HD has also been followed with PET. ${ }^{18}$ FDG PET series have reported that striatal glucose metabolism declines annually by around $3 \%$ from baseline levels, whereas striatal $\mathrm{D}_{1}$ and $\mathrm{D}_{2}$ binding falls at an annual rate of 3-6\% in early HD. ${ }^{48,52}$

\section{TRANSPLANTATION IN PD}

\section{Dopaminergic studies}

Although dopaminergic grafts have been shown to express DATs at postmortem, ${ }^{53}$ a recent PET study was unable to detect significant increases in DAT binding after implantation of fetal mesencephalic cells, even though putamen ${ }^{18} \mathrm{~F}$-dopa uptake improved. ${ }^{54}$ Currently, there are no reported DTBZ PET data on the expression and survival of VMAT2 in mesencephalic grafts. Given this, this section will concentrate on ${ }^{18} \mathrm{~F}$-dopa PET findings in PD.

There has been only one ${ }^{18} \mathrm{~F}$-dopa PET report concerning autologous implants of adrenal tissue in PD. ${ }^{55}$ Five patients received implants to the right caudate, but no convincing PET evidence of graft function was found 6 weeks postoperatively. A pilot open study studying the safety and efficacy of porcine mesencephalic xenografts when transplanted unilaterally into striatum in $12 \mathrm{PD}$ patients with severe disease has also been reported. ${ }^{56}$ In this series, only 2 of 10 evaluable patients showed significant improvements in locomotor disability, rated with the UPDRS, but no increases in striatal ${ }^{18} \mathrm{~F}$-dopa uptake were evident.

Serial ${ }^{18}$ F-dopa PET data were initially reported in an open manner for small series of younger PD patients who received unilateral or bilateral implants of human fetal mesencephalic cells using different operative approaches and methods of cell preparation. The majority of these showed convincing ${ }^{18} \mathrm{~F}$-dopa PET evidence of graft function sustained from 6 months to 10 years of follow-up. ${ }^{57-65}$ Two of these parkinsonian patients were 1-methyl-4-phenyl1,2,3,6-tetrahydro-pyridine-exposed individuals. ${ }^{66}$

The Lund group ${ }^{61}$ reported up to 6-year follow-up data on six PD patients who received unilateral dorsal putamen (and in two cases, head of caudate) implants of human 6- to 9-week gestation fetal mesencephalic cells. All patients received prednisolone, cyclosporin, and azathoprine immunosuppressive cover. At 1 year after transplantation, there was a mean $68 \%$ increase in putamen ${ }^{18} \mathrm{~F}$-dopa uptake on the transplanted side but only a $6 \%$ increase in transplanted caudate ${ }^{18} \mathrm{~F}$-dopa uptake. Nongrafted putamen showed a corresponding mean $25 \%$ decrease in ${ }^{18} \mathrm{~F}$-dopa uptake. The mean UPDRS "off" motor score fell by $18 \%$ after 1 year, four of the six cases individually improving, and mean time in "off" fell by $34 \%$. One of these six cases ceased to require dopaminergic medication and his putamen ${ }^{18} \mathrm{~F}$-dopa uptake reached normal levels. Despite this, for the group there was a dissociation between the relatively modest improvement in UPDRS scores and the more marked increase in putamen ${ }^{18} \mathrm{~F}$-dopa uptake.

Five of these six PD patients subsequently received bilateral striatal implants of fetal dopaminergic cells. ${ }^{64}$ After an additional 12-18 months, there was a mean $85 \%$ increase in ${ }^{18} \mathrm{~F}$-dopa uptake by the putamen receiving the second graft, whereas there was no overall change in mean ${ }^{18}$ F-dopa uptake by the previously transplanted putamen, suggesting that dopamine storage capacity had now plateaued. Three of the five patients receiving a second graft were judged to have improved as evidenced by reduced bradykinesia, time in "off," and lower levodopa requirements. The other two worsened, but one of these developed features suggestive of multiple system atrophy.

Remy et al. ${ }^{65}$ reported up to 2 -year ${ }^{18}$ F-dopa PET follow-up data on five PD patients, all of whom received unilateral putamen implants and two of whom received unilateral caudate implants of human fetal mesencephalic cells. At 1 year after transplantation, there was a 
$61 \%$ increase in ${ }^{18} \mathrm{~F}$-dopa uptake in grafted putamen, but there were no significant changes in implanted caudate ${ }^{18} \mathrm{~F}$-dopa uptake. Individual putamen $K_{\mathrm{i}}$ values before and after grafting correlated with percentage times "on," and timed finger dexterity when "off." The authors concluded that raising putamen ${ }^{18} \mathrm{~F}$-dopa uptake to within two SDs of the normal mean via cell implantation should be sufficient to restore normal limb function in PD.

The Tampa group ${ }^{58}$ presented 6-month follow-up data for four PD patients who received bilateral fetal mesencephalic tissue implants into posterior putamen. After transplantation, these workers observed 53\% and 33\% increases in right and left putamen ${ }^{18} \mathrm{~F}$-dopa uptake. All patients improved clinically when "off" with a mean $37 \%$ decrease in total UPDRS score and mean $41 \%$ increase in Schwab and England disability score. No significant changes in "on" ratings were noted. Percentage of time spent "off" fell by $65 \%$ and time "on" with dyskinesias fell by $92 \%$. Gait improved in three of these four patients and freezing attacks resolved in two. Two of the transplanted PD patients in the Florida series subsequently died from unrelated causes and at postmortem viable tyrosine hydroxylase staining graft tissue forming connections with host neurons was seen. ${ }^{67}$ This finding supports the view that ${ }^{18} \mathrm{~F}$-dopa PET is measuring graft function rather than simply reflecting host neuronal sprouting as a reaction to foreign tissue or the presence of blood-brain barrier breakdown. In a 2-year follow-up report on six cases, the workers noted that the mean total UPDRS "off" score had improved by $32 \%$ and that mean percentage of time "on" without dyskinesia during the waking day had improved from $22 \%$ to $60 \%(p<0.05)$. Individual increases in putamen ${ }^{18} \mathrm{~F}$-dopa uptake seen over the first 12 months correlated with improvements in disability scores.

More recently, the Lund group performed bilateral putamen and caudate transplantations on four more PD cases (mean age, 50 years; clinical disease duration, 13 years). ${ }^{63}$ By 6 months after surgery, mean putamen ${ }^{18} \mathrm{~F}$ dopa uptake had increased by $53 \%$, whereas caudate uptake increased by $24 \%$ (FIG. 1). Graft dopamine storage capacity then plateaued, being increased by $57 \%$ in putamen and $28 \%$ in caudate 20 months after transplantation. Motor disability, rated with the UPDRS, continuously improved over the 20 months, with scores falling by $50 \%$ despite the stabilization of dopamine storage capacity at 9 months. This suggested that graft function and integration continues to mature. It was possible to reduce levodopa dosage by a mean of $50 \%$, and one of the four patients was able to cease taking levodopa altogether.

Given the encouraging findings of these pilot open series, two major double-blind controlled trials on the efficacy of implantation of human fetal cells in PD were sponsored by the National Institutes of Health (NIH) in the United States. The first trial involved 40 patients, who ranged from 34 to 75 years of age and had established severe PD (mean duration, 14 years). ${ }^{68}$ Patients were randomized to receive either implants of human fetal mesencephalic tissue or undergo sham surgery. They were followed for 1 year after surgery with a subsequent extension to 3 years. In the transplant recipients, mesencephalic tissue from four embryos cultured for up to 1 month was implanted into the putamen bilaterally (two embryos per side) via a frontal approach. In the patients who underwent sham surgery, holes were drilled in the frontal skull but the dura was not penetrated. No immunotherapy was used.

The transplanted patients showed no significant improvement in the primary endpoint, clinical global impression, at 1 year, although there was a significant mean $18 \%$ improvement in the mean UPDRS motor score compared with the sham-surgery group when tested in the morning before receiving medication $(p=0.04)$.

This modest clinical improvement contrasted with a $40 \%$ increase in putamen ${ }^{18} \mathrm{~F}$-dopa uptake. Improvement in disability was most evident for patients under 60 years of age (34\% improvement; $p=0.005$ ), despite a similar increase in putamen ${ }^{18} \mathrm{~F}$-dopa uptake in both younger and older subgroups. By 3 years after surgery, mean total UPDRS scores were improved by $38 \%$ in the younger and $14 \%$ in the older transplanted groups (both $p<0.01$ ) without a further increase in dopamine storage capacity. It was in this trial that the problem of "off" dystonia and dyskinesias in transplanted patients first came to light, with $15 \%$ of grafted patients experiencing this adverse event, even after reduction or termination of levodopa.

In the second NIH trial, 34 patients were randomized to receive bilateral implants of blocks of fetal mesencephalic tissue into posterior putamen (either four fetuses or one fetus per side) or had sham surgery (a partial burr hole without penetration of the dura). ${ }^{69}$ Fetal tissue was cultured for up to $48 \mathrm{~h}$ before transplantation, and all patients received immunosuppression for the first 6 months after surgery. The trial duration was 2 years, and the primary outcome variable was change in "off" UPDRS motor score. Thirty-one patients completed the trial; two patients died during and another three died after the trial from unrelated causes.

At postmortem, the transplanted patients showed significantly greater tyrosine hydroxylase staining in the putamen than the sham surgery patients with graft innervation of intrinsic striatal cells evident. Mean putamen: occipital ${ }^{18} \mathrm{~F}$-dopa uptake ratios were unchanged in the control patients but showed 20\% and 30\% increases ( $p<$ $0.001)$ in patients receiving tissue from one and four fetuses, respectively. The mean UPDRS motor score off medication for the controls deteriorated by 9.4 and 3.5 points over 2 years for the control group and one fetus group and improved by 0.7 points for the four fetus 
Pre-graft
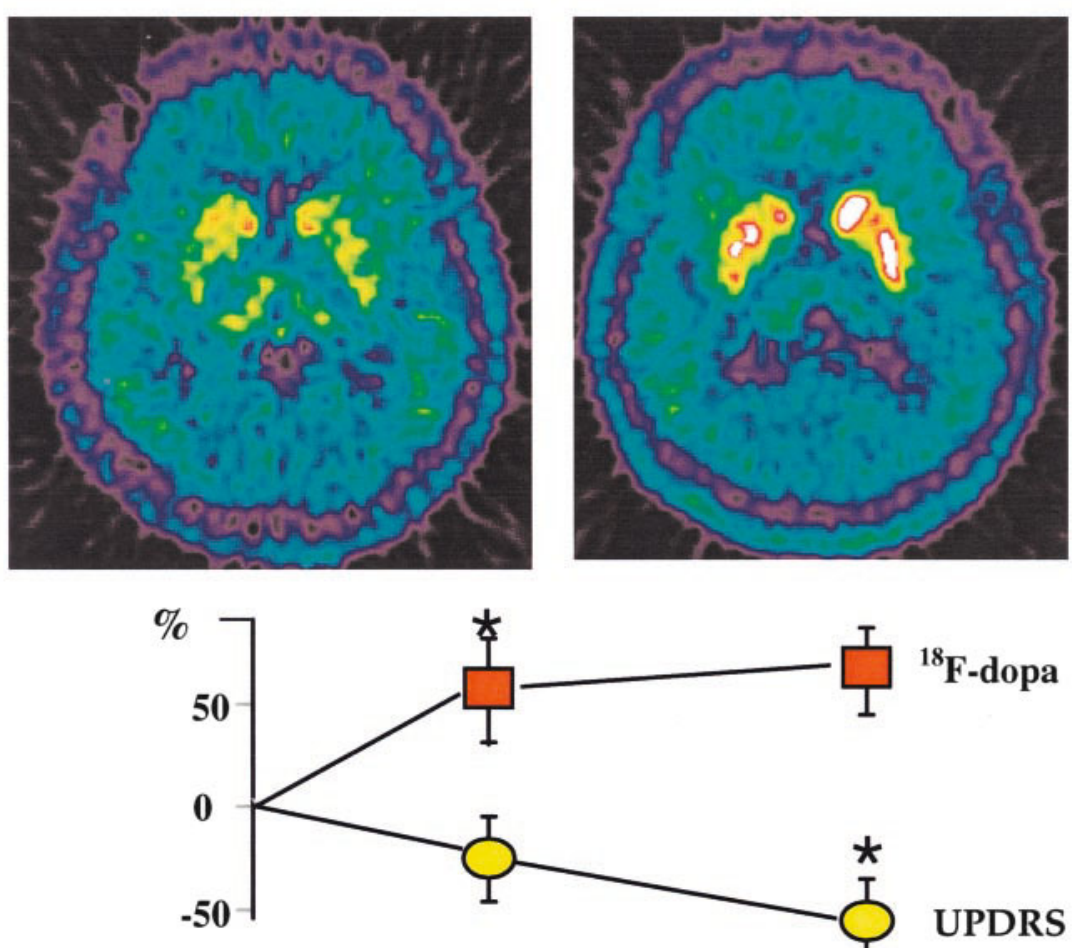
$\mathrm{rCBF}$ increase
$\mathrm{ml} / 100 \mathrm{ml} / \mathrm{min}$

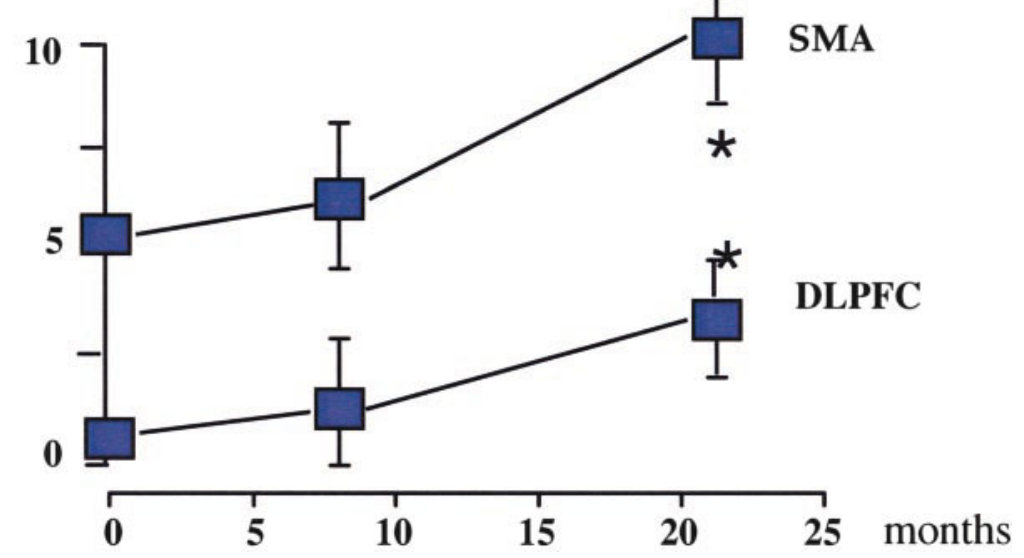

Fig. 1. The PET scans show striatal ${ }^{18} \mathrm{~F}$-dopa uptake before and 2 years after bilateral caudate and putamen implantation of fetal mesencephalic cells into a PD case. The graphs show recovery of putamen ${ }^{18} \mathrm{~F}$-dopa uptake, locomotor disability on the UPDRS scale, and mesial premotor and prefrontal activation during a motor task. Reprinted with permission from the Medical Research Council Clinical Sciences Centre.

group. These clinical changes were not significantly different overall (four fetus $v s$ controls, $p=0.096$ ) but, interestingly, at 6 months (before discontinuation of immunosuppression) the transplanted groups were both significantly improved $(p<0.05)$. Interestingly, patients with less severe disease (UPDRS $<49$ ) who received transplantation with four donors per side $(\mathrm{n}=6)$ improved by an adjusted mean score of 1.5 , whereas those in the placebo group $(\mathrm{n}=6)$ deteriorated by $21.4(p=$ 0.005 ), although no age effect was noted. No significant differences in "on" time without dyskinesias, total "off" time, Activities of Daily Living scores, or levodopa dose required were evident between the groups. "Off" period dyskinesias were a problem in 13 of 23 implanted patients but were not seen in the control arm.

In summary, despite both histological and ${ }^{18} \mathrm{~F}$-dopa PET evidence of graft function, neither of these controlled double-blind trials demonstrated clinical efficacy with their primary endpoints and improvements were modest on secondary measures. There were indications, however, that younger, less severely affected patients could benefit from intrastriatal implantation of human fetal dopamine cells. In both of these trials, "off" period dyskinesias were problematic. 


\section{Brain activation and dopamine release}

To determine whether movement-related premotor and prefrontal cortex activation, both impaired in PD patients, improves as a result of striatal fetal dopaminergic cell implantation, four PD patients from the Lund series who received bilateral fetal transplants into caudate and putamen were serially studied with $\mathrm{H}_{2}{ }^{15} \mathrm{O}$ PET at baseline and twice more over 2 years after surgery. ${ }^{70}$ Activation-induced increases in $\mathrm{rCBF}$ were measured while subjects performed paced joystick movements every $4 \mathrm{~s}$ in freely selected directions using their right hand. Regional levels of activation related to the joystick movements were compared pre- and postimplantation using SPM. Although a significant 53\% improvement in striatal dopaminergic function was present by 6 months of implantation in the PD patients, which subsequently plateaued, improvements in the "off" UPDRS score and movement-related frontal activation improved linearly over the course of the 2 years, at which time they reached significance (FIG. 1). Levels of SMA rCBF increase induced during arm movement were 5\% at baseline, $6 \%$ (NS) by 7 months after surgery, and $10 \%(p<0.01) 20$ months after grafting.

The fact that clinical improvement paralleled the restoration of levels of frontal activation rather than improvements in striatal dopamine storage capacity, and continued after the latter had plateaued, suggests that relief of symptoms after implantation of fetal dopaminergic cells requires maturation of dopamine release from these cells and functional reafferentation of striatothalamocortical circuitries, along with an increased ability to produce and store dopamine.

Piccini and coworkers ${ }^{71}$ have demonstrated that synaptic dopamine release from nigral transplants can be monitored using ${ }^{11} \mathrm{C}$-raclopride PET. They reported changes in striatal dopamine D2 receptor availability after an amphetamine challenge in a unilaterally grafted PD patient. Ten years after implantation of fetal dopamine cells into the right putamen, the graft had restored both basal and drug-induced dopamine release to normal levels (FIG. 2). This was associated with marked clinical benefit and normal levels of dopamine storage, as evidenced by ${ }^{18} \mathrm{~F}$-dopa uptake, in the grafted putamen. These data indicate that, despite an ongoing disease process, grafted neurons can continue for a decade to store and release dopamine and give rise to substantial symptomatic relief.

\section{Mechanisms of "off" dyskinesias following transplantation}

The pathogenesis of post-transplant dyskinesias present when off medication remains unclear. One possibility is excessive or aberrant dopaminergic stimulation, and this viewpoint is supported by two observations: 1) in the Denver series, those patients with persistent dyskinesias off medication after transplantation showed unexpected and asymmetric increases in ${ }^{18} \mathrm{~F}$-dopa uptake in the nongrafted ventral striatum, ${ }^{72}$ and 2) two patients who underwent surgery in the Tampa double-blind trial had "off" dyskinesia associated with increased caudate ${ }^{18} \mathrm{~F}$-dopa uptake in one and greater than expected striatal ${ }^{11} \mathrm{C}$-raclopride displacement after levodopa in both cases. ${ }^{73}$ Additionally, in both patients, ${ }^{11}$ C-raclopride binding in the "off" state was reduced below normal, suggesting that striatal D2 receptors were occupied by excessive release of DA both basally and after levodopa.

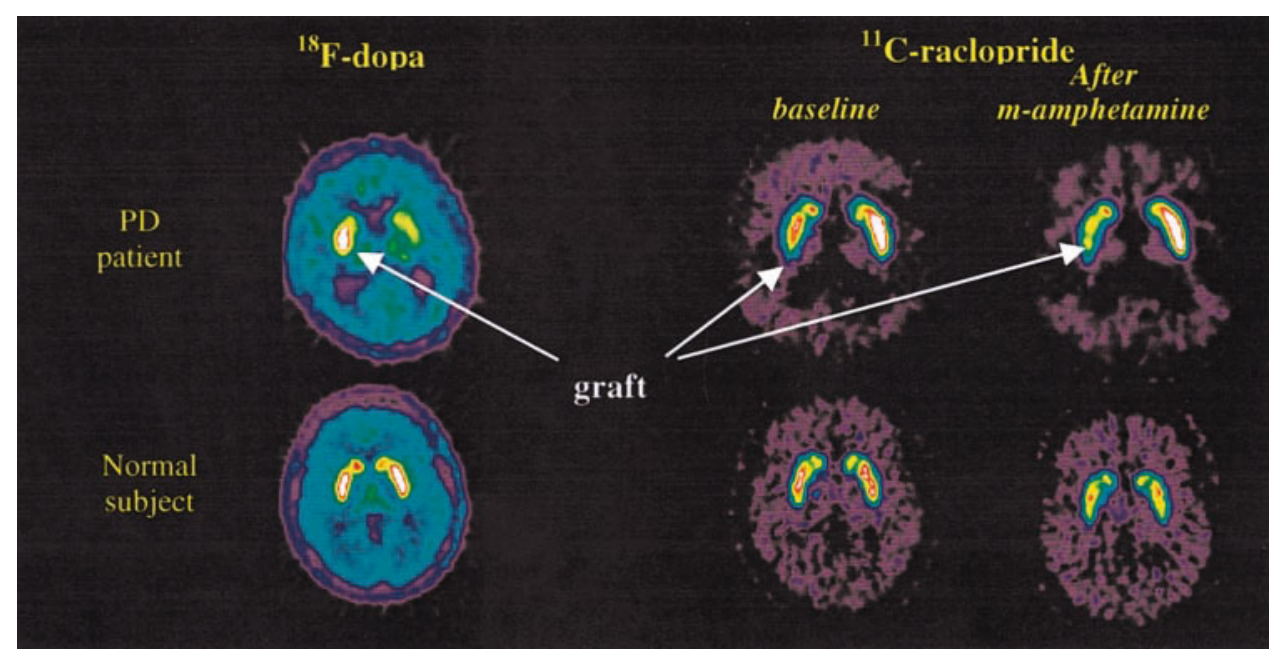

Fig. 2. Striatal ${ }^{18} \mathrm{~F}$-dopa uptake and ${ }^{11} \mathrm{C}$-raclopride binding before and after an amphetamine challenge in a PD patient unilaterally grafted into putamen and a normal subject. The baseline putamen ${ }^{11} \mathrm{C}$-raclopride binding is normal on the grafted and raised on the ungrafted side in PD, reflecting restored dopamine tone in the former and reduced in the latter. An amphetamine challenge reduces putamen ${ }^{11} \mathrm{C}$-raclopride binding normally in the grafted but not the ungrafted side. Reprinted with permission from the Medical Research Council Clinical Sciences Centre. 
Against this viewpoint, however, is the fact that the open Swedish series noted "off" dyskinesias in only a minority of cases and these were relatively mild despite normalization of putamen ${ }^{18} \mathrm{~F}$-dopa uptake on occasion. ${ }^{74}$ Severity of "off" dyskinesia in affected patients was inversely correlated with baseline ${ }^{18} \mathrm{~F}$-dopa uptake before surgery rather than postimplant increases and also correlated with the amount of fetal tissue implanted. The authors argued against "off" dyskinesias arising as a consequence of excessive dopaminergic function. In support, in the Tampa double-blind trial there was again no obvious relationship between the emergence of increased dyskinesia and increases in ${ }^{18} \mathrm{~F}$-dopa uptake.

\section{TRANSPLANTATION IN HD}

Transplantation of embryonic striatal tissue into the degenerated striatum of rat and primate models of HD has been shown to be safe and has demonstrated good graft survival with differentiation and integration of striatal grafts into host striatum. Recovery of striatal dopamine $\mathrm{D} 2$ binding in rats and marmosets lesioned with ibotenic acid after implantation of fetal striatal tissue has been detected with ${ }^{11} \mathrm{C}$-raclopride PET. ${ }^{75-77}$ In primate models, recovery of skilled motor and cognitive performance has been reported within 2 months and improvements in dystonia scores within 4-5 months of grafting. ${ }^{78,79}$ Physiological, neurochemical, and anatomical studies have shown that a partial restoration of striatal input and output circuitry by implanted striatal neurons does occur, but the time course of this in primates and humans remains unclear.

Clinical studies of the possible therapeutic effects of striatal allografts in patients with HD are now running in the United States, France, and England. Bachoud-Levi and coworkers ${ }^{80}$ reported that three of five HD patients implanted with striatal cells from 8- to 9-week gestation fetuses improved over the course of 12 months, whereas two deteriorated. In the three that clinically improved, it was possible to detect striatal graft function, as evidenced by islands of increased glucose utilization seen with ${ }^{18}$ FDG PET, but not in the two cases who subsequently deteriorated.

In an open series in Tampa, seven symptomatic HD patients had bilateral implantation of between two and eight fetal striata per side in two staged procedures. ${ }^{81}$ Again, tissue was dissected from the lateral half of the lateral ventricular eminence of donors 8-9 weeks after conception. Subjects received cyclosporine for 6 months. These patients were studied with ${ }^{18} \mathrm{FDG},{ }^{11} \mathrm{C}$ $\mathrm{SCH} 23390$, and ${ }^{11} \mathrm{C}$-raclopride PET. Monitoring striatal dopamine receptor binding has a theoretical advantage over monitoring glucose metabolism because regeneration of dopamine receptors should provide a clear indi-
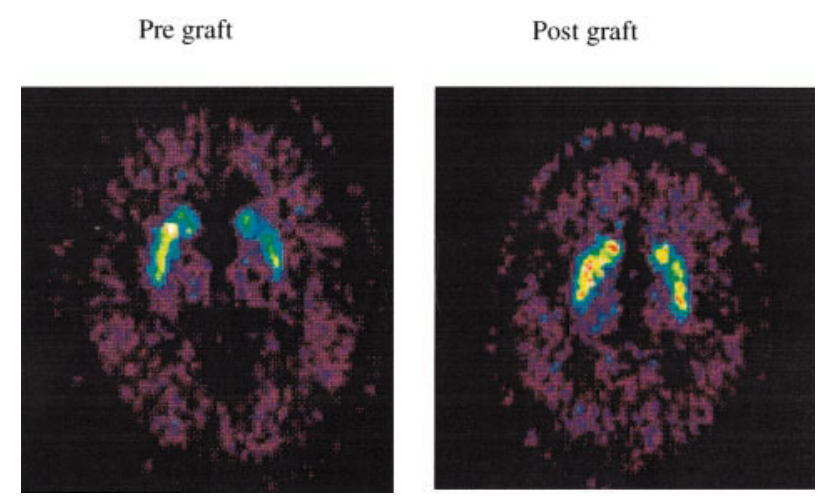

Fig. 3. Striatal ${ }^{11} \mathrm{C}$-raclopride binding in an HD patient before and after implantation of fetal striatal cells. Regeneration of D2 sites can be seen after grafting. Reprinted with permission from the Medical Research Council Clinical Sciences Centre.

cation of graft function, whereas improved glucose metabolism could also reflect active graft rejection (FIG. 3).

Overall, there was no significant change in mean unified HD rating scale (UHDRS) motor scores $(32.9 \pm 6.2$ at baseline and $29.7 \pm 7.512$ months after surgery); however, if one subject who deteriorated because of development of symptomatic bilateral subdural hematomata was excluded, a significant improvement in mean UHDRS motor scores was seen $(33.8 \pm 6.2$ at baseline and $27.5 \pm 5.2$ at 12 months; $p=0.03$ ). PET showed no significant change in striatal glucose metabolism, dopamine D1, or D2 receptor binding 11 months after implantation; however, there was a trend toward a correlation between changes in striatal D1 binding and UHDRS scores. In this series, three subjects developed subdural hemorrhages, and two required surgical drainage. One subject died 18 months after surgery, and autopsy demonstrated clearly demarcated grafts of typical developing striatal morphology, with host-derived dopaminergic fibers extending into the grafts and no evidence of immune rejection.

To summarize, two open series have now demonstrated that transplantation of human fetal striatal cells is feasible in HD, and survival of transplanted cells has been demonstrated on occasion both with FDG-PET and at postmortem. Improvement in disability has been inconsistent and mild, and patients appear to be at some risk for subdural hematomata after transplantation surgery.

\section{CONCLUSIONS}

Functional imaging has provided objective evidence that grafts of fetal dopaminergic tissue can survive in PD patients and increase striatal dopamine storage capacity. There appears, however, to be a dissociation between graft ${ }^{18} \mathrm{~F}$-dopa uptake and clinical improvement that correlates better with levels of cortical activation during tasks. This suggests that fetal tissue needs to mature and form connections with the host striatum before function of corticostriatal loops can be restored and may explain 
the failure of many PD patients to improve clinically despite apparent graft function. Two small open series of transplanted HD cases have shown inconsistent PET evidence of graft function and clinical response. In the future, it is likely that PET and SPECT will be used to study ways of improving graft viability with antiapoptotic agents and neuroprotective agents, the inflammatory responses to transplantation using tracers such as the activated microglial marker ${ }^{11} \mathrm{C}$-PK11195 PET, and for studying the efficacy of implanted transformed and stem cell lines. The failure of some patients to respond to grafts clinically despite the PET and SPECT evidence of implanted tissue function, however, implies that functional imaging is not currently suitable for use as a surrogate endpoint.

\section{REFERENCES}

1. Firnau G, Sood S, Chirakal R et al. Cerebral metabolism of $6-[18$ F]fluoro-L-3,4-dihydroxyphenylalanine in the primate. $J$ Neurochem 48:1077-1082, 1987.

2. Patlak C, Blasberg RG. Graphical evaluation of blood-to-brain transfer constants from multiple-time uptake data. Generalisations. J Cereb Blood Flow Metab 5:584-590, 1985.

3. Brooks DJ, Salmon EP, Mathias CJ et al. The relationship between locomotor disability, autonomic dysfunction, and the integrity of the striatal dopaminergic system, in patients with multiple system atrophy, pure autonomic failure, and Parkinson's disease, studied with PET. Brain 113:1539-1552, 1990.

4. Rakshi JS, Uema T, Ito K et al. Frontal, midbrain and striatal dopaminergic function in early and advanced Parkinson's disease: a 3D [(18)F]-dopa-PET study. Brain 122:1637-1650, 1999.

5. Vingerhoets FJG, Schulzer M, Caine DB, Snow BJ. Which clinical sign of Parkinson's disease best reflects the nigrostriatal lesion? Ann Neurol 41:58-64, 1997.

6. Hadjiconstantinou M, Wemlinger TA, Sylvia CP et al. Aromatic L-amino acid decarboxylase activity of mouse striatum is modulated via dopamine receptors. J Neurochem 60:2175-2180, 1993.

7. Frost JJ, Rosier AJ, Reich SG et al. Positron emission tomographic imaging of the dopamine transporter with 11C-WIN 35,428 reveals marked declines in mild Parkinson's disease. Ann Neurol 34:423431, 1993.

8. Guttman M, Burkholder J, Kish SJ et al. [11C]RTI-32 PET studies of the dopamine transporter in early dopa-naive Parkinson's disease: implications for the symptomatic threshold. Neurology 48: 1578-1583, 1997.

9. Marek K, Seibyl JP, Zoghbi SS et al. [I-123] $\beta$-CIT SPECT imaging demonstrates bilateral loss of dopamine transporters in hemiParkinson's disease. Neurology 46:231-237, 1996.

10. Booij J, Tissingh G, Boer GJ et al. [123I]FP-CIT SPECT shows a pronounced decline of striatal dopamine transporter labelling in early and advanced Parkinson's disease. J Neurol Neurosurg Psychiat 62:133-140, 1997.

11. Lee CS, Samii A, Sossi V et al. In vivo positron emission tomographic evidence for compensatory changes in presynaptic dopaminergic nerve terminals in Parkinson's disease. Ann Neurol 47: 493-503, 2000.

12. Salmon EP, Brooks DJ, Leenders KL et al. A two-compartment description and kinetic procedure for measuring regional cerebral [11C]nomifensine uptake using positron emission tomography. J Cereb Blood Flow Metab 10:307-316, 1990.

13. Innis RB, Marek KL, Sheff K et al. Effect of treatment with L-dopa/carbidopa or L-selegiline on striatal dopamine transporter SPECT imaging with [I-123] $\beta$-CIT. Mov Disord 14:436-442, 1999.

14. Frey KA, Koeppe RA, Kilbourn MR et al. Pre-synaptic monoaminergic vesicles in Parkinson's disease and normal aging. Ann Neurol 40:873-884, 1996.
15. Playford ED, Brooks DJ. In vivo and in vitro studies of the dopaminergic system in movement disorders. Cerebrovasc Brain Metab Rev 4:144-171, 1992.

16. Brooks DJ, Ibanez V, Sawle GV et al. Striatal D2 receptor status in Parkinson's disease, striatonigral degeneration, and progressive supranuclear palsy, measured with 11C-raclopride and PET. Ann Neurol 31:184-192, 1992.

17. Rinne JO, Laihinen A, Rinne UK et al. PET study on striatal dopamine D2 receptor changes during the progression of early Parkinson's disease. Mov Disord 8:134-138, 1993.

18. Antonini A, Schwarz J, Oertel WH et al. [11C]raclopride and positron emission tomography in previously untreated patients with Parkinson's disease: influence of L-dopa and lisuride therapy on striatal dopamine D2-receptors. Neurology 44:1325-1329, 1994.

19. Hagglund J, Aquilonius SM, Eckernas SA et al. Dopamine receptor properties in Parkinson's disease and Huntington's chorea evaluated by positron emission tomography using $11 \mathrm{C}-\mathrm{N}$-methyl-spiperone. Acta Neurol Scand 75:87-94, 1987.

20. Turjanski N, Weeks R, Dolan R et al. Striatal D1 and D2 receptor binding in patients with Huntington's disease and other choreas: a PET study. Brain 118:689-696, 1995.

21. Brucke T, Podreka I, Angelberger P et al. Dopamine D2 receptor imaging with SPECT: studies in different neuropsychiatric disorders. J Cereb Blood Flow Metab 11:220-228, 1991.

22. Weeks RA, Piccini P, Harding AE, Brooks DJ. Striatal D1 and D2 dopamine receptor loss in asymptomatic mutation carriers of Huntington's disease. Ann Neurol 40:49-54, 1996.

23. Volkow ND, Wang G-J, Fowler JS et al. Imaging endogenous dopamine competition with [11C]raclopride in the human brain. Synapse 16:255-262, 1994.

24. Chugani DC, Ackermann RF, Phelps ME. In vivo $3 \mathrm{H}$-spiperone binding: evidence for accumulation in corpus striatum by agonist mediated receptor internalisation. J Cereb Blood Flow Metab 8:291-303, 1988.

25. De La Fuente-Fernandez R, Lu JQ, Sossi V et al. Biochemical variations in the synaptic level of dopamine precede motor fluctuations in Parkinson's disease: PET evidence of increased dopamine turnover. Ann Neurol 49:298-303, 2001.

26. Laruelle M, Abi-Dargham A, van Dyck CH et al. SPECT imaging of striatal dopamine release after amphetamine challenge. $J$ Nucl Med 36:1182-1190, 1995.

27. Goerendt IK, Messa C, Lawrence AD et al. Dopamine release during sequential finger movements in health and Parkinson's disease: a PET study. Brain 126:312-325, 2003.

28. Morris ED, Fisher RE, Alpert NM et al. In vivo imaging of neuromodulation using positron emission tomography: optimal ligand characteristics and task length for detection of activation. Hum Brain Mapp 3:35-55, 1995.

29. Piccini P, Pavese N, Brooks DJ. Endogenous dopamine release after pharmacological challenges in Parkinson's disease. Ann Neurol 53:647-653, 2003.

30. Wolfson LI, Leenders KL, Brown LL, Jones T. Alterations of regional cerebral blood flow and oxygen metabolism in Parkinson's disease. Neurology 35:1399-1405, 1985.

31. Miletich RS, Chan T, Gillespie M et al. Contralateral basal ganglia metabolism is abnormal in hemiparkinsonian patients. An FDGPET study. Neurology 38:S260, 1988.

32. Eidelberg D, Moeller JR, Dhawan V et al. The metabolic topography of parkinsonism. J Cereb Blood Flow Metab 14:783-801, 1994.

33. Eidelberg D, Moeller JR, Ishikawa T et al. Assessment of disease severity in Parkinsonism with fluorine-18-fluorodeoxyglucose and PET. J Nucl Med 36:378-383, 1995.

34. Playford ED, Jenkins IH, Passingham RE et al. Impaired mesial frontal and putamen activation in Parkinson's disease: a PET study. Ann Neurol 32:151-161, 1992.

35. Jahanshahi M, Jenkins IH, Brown RG et al. Self-initiated versus externally-triggered movements: measurements of regional cerebral blood flow and movement-related potentials in normals and Parkinson's disease. Brain 118:913-933, 1995.

36. Rascol O, Sabatini U, Chollet $F$ et al. Normal activation of the supplementary motor area in patients with Parkinson's disease 
undergoing long-term treatment with levodopa. $J$ Neurol Neurosurg Psychiatry 57:567-571, 1994.

37. Jenkins IH, Fernandez W, Playford ED et al. Impaired activation of the supplementary motor area in Parkinson's disease is reversed when akinesia is treated with apomorphine. Ann Neurol 32:749-757, 1992.

38. Fukuda M, Mentis M, Ghilardi MF et al. Functional correlates of pallidal stimulation for Parkinson's disease. Ann Neurol 49:155164, 2001.

39. Ceballos-Baumann AO, Boecker H, Bartenstein $\mathrm{P}$ et al. A positron emission tomographic study of subthalamic nucleus stimulation in Parkinson disease-enhanced movement-related activity of motorassociation cortex and decreased motor cortex resting activity. Arch Neurol 56:997-1003, 1999.

40. Kuhl DE, Phelps ME, Markham $\mathrm{CH}$ et al. Cerebral metabolism and atrophy in Huntington's disease determined by 18FDG and computed tomographic scans. Ann Neurol 12:425-434, 1982.

41. Hayden MR, Martin WRW, Stoessl AJ et al. Positron emission tomography in the early diagnosis of Huntington's disease. Neurology 36:888-894, 1986.

42. Leenders KL, Frackowiak RSJ, Quinn N, Marsden CD. Brain energy metabolism and dopaminergic function in Huntington's disease measured in vivo using positron emission tomography. Mov Disord 1:69-77, 1986.

43. Young AB, Penney JB, Starosta-Rubinstein S et al. PET scan investigations of Huntington's disease: cerebral metabolic correlates of neurological features and functional decline. Ann Neurol 20:296-303, 1986.

44. Berent S, Giordani B, Lehtinen S et al. Positron emission tomographic scan investigations of Huntington's disease: cerebral metabolic correlates of cognitive function. Ann Neurol 23:541-546, 1988.

45. Kuwert T, Lange HW, Langen KJ et al. Cortical and subcortical glucose consumption measured by PET in patients with Huntington's disease. Brain 113:1405-1423, 1990.

46. Grafton ST, Mazziotta JC, Pahl JJ et al. A comparison of neurological, metabolic, structural, and genetic evaluations in persons at risk for Huntington's disease. Ann Neurol 28:614-621, 1990.

47. Hayden MR, Hewitt J, Stoessl AJ et al. The combined use of positron emission tomography and DNA polymorphisms for preclinical detection of Huntington's disease. Neurology 37:14411447, 1987.

48. Antonini A, Leenders KL, Spiegel R et al. Striatal glucose metabolism and dopamine D-2 receptor binding in asymptomatic gene carriers and patients with Huntington's disease. Brain 119:20852095, 1996.

49. Morrish PK, Rakshi JS, Sawle GV, Brooks DJ. Measuring the rate of progression and estimating the preclinical period of Parkinson's disease with $[18 \mathrm{~F}]$ dopa PET. J Neurol Neurosurg Psychiatry 64: 314-319, 1998.

50. Nurmi E, Ruottinen HM, Kaasinen V et al. Progression in Parkinson's disease: a positron emission tomography study with a dopamine transporter ligand. Ann Neurol 47:804-808, 2000.

51. Marek K, Innis R, van Dyck C et al. [123I] $\beta$-CIT SPECT imaging assessment of the rate of Parkinson's disease progression. Neurology 57:2089-2094, 2001.

52. Andrews TC, Weeks RA, Turjanski N et al. Huntington's disease progression PET and clinical observations. Brain 122:2353-2363, 1999.

53. Kordower JH, Rosenstein JM, Collier TJ et al. Functional fetal nigral grafts in a patient with Parkinson's disease: chemoanatomic, ultrastructural, and metabolic studies. J Comp Neurol 370:203230, 1996.

54. Cochen V, Ribeiro MJ, Nguyen JP et al. Transplantation in Parkinson's disease: PET changes correlate with the amount of grafted tissue. Mov Disord 18:928-932, 2003.

55. Guttman M, Burns RS, Martin WR et al. PET studies of Parkinsonian patients treated with autologous adrenal implants. Can J Neurol Sci 16:305-309, 1989.

56. Fink JS, Schumacher JM, Ellias SL et al. Porcine xenografts in
Parkinson's disease and Huntington's disease patients: preliminary results. Cell Transplant 9:273-278, 2000.

57. Freed CR, Breeze RE, Rosenberg NL et al. Survival of implanted fetal dopamine cells and neurologic improvement 12 to 46 months after transplantation for Parkinson's disease. N Engl J Med 327: 1549-1555, 1992.

58. Freeman TB, Olanow CW, Hauser RA et al. Bilateral fetal nigral transplantion into the post-commisural putamen as a treatment for Parkinson's disease: six months follow-up. Ann Neurol 38:379388, 1995.

59. Hauser RA, Freeman TB, Snow BJ et al. Long-term evaluation of bilateral fetal nigral transplantation in Parkinson disease. Arch Neurol 56:179-187, 1999.

60. Lindvall O, Sawle G, Widner H et al. Evidence for long term survival and function of dopaminergic grafts in progressive Parkinson's disease. Ann Neurol 35:172-180, 1994.

61. Wenning GK, Odin P, Morrish PK et al. Short- and long-term survival and function of unilateral intrastriatal dopaminergic grafts in Parkinson's disase. Ann Neurol 42:95-107, 1997.

62. Lindvall O. Cerebral implantation in movement disorders: state of the art. Mov Disord 14:201-205, 1999.

63. Brundin P, Pogarel O, Hagell P et al. Bilateral caudate and putamen grafts of embryonic mesencephalic tissue treated with lazaroids in Parkinson's disease. Brain 123:1380-1390, 2000.

64. Hagell P, Schrag AE, Piccini P et al. Sequential bilateral transplantation in Parkinson's disease: effects of the second graft. Brain 122:1121-1132, 1999.

65. Remy P, Samson Y, Hantraye P et al. Clinical correlates of [18F]fluorodopa uptake in five grafted parkinsonian patients. Ann Neurol 38:580-588, 1995

66. Widner H, Tetrud J, Rehncrona $\mathrm{S}$ et al. Bilateral fetal mesencephalic grafting in two patients with parkinsonism induced by 1-methyl-4-phenyl-1,2,3,6-tetrahydro-pyridine (MPTP). $N$ Engl J Med 327:1556-1563, 1992.

67. Kordower JH, Freeman TB, Snow BJ et al. Neuropathological evidence of graft survival and striatal reinnervation after the transplantation of fetal mesencephalic tissue in a patient with Parkinson's disease. N Engl J Med 332:1118-1124, 1995.

68. Freed CR, Greene PE, Breeze RE et al. Transplantation of embryonic dopamine neurons for severe Parkinson's disease. $N$ Engl $J$ Med 344:710-719, 2001.

69. Olanow CW, Goetz CG, Kordower JH et al. A double-blind controlled trial of bilateral fetal nigral transplantation in Parkinson's disease. Ann Neurol 54:403-414, 2003.

70. Piccini P, Lindvall O, Bjorklund A et al. Delayed recovery of movement-related cortical function in Parkinson's disease after striatal dopaminergic grafts. Ann Neurol 48:689-695, 2000

71. Piccini P, Brooks DJ, Bjorklund A et al. Dopamine release from nigral transplants visualised in vivo in a Parkinson's patient. Nat Neurosci 2:1137-1140, 1999.

72. Ma Y, Feigin A, Dhawan V et al. Dyskinesia after fetal cell transplantation for parkinsonism: a PET study. Ann Neurol 52: 628-634, 2002.

73. Huang Z, De la Fuente-Fernandez R, Hauser RA et al. Dopaminergic alteration in Parkinson's patients with "off period" dyskinesia following striatal embryonic mesencephalic transplant. $\mathrm{Neu}$ rology 60 [Suppl 1]:A126 (Abstract), 2003.

74. Hagell P, Piccini P, Bjorklund A et al. Dyskinesias following neural transplantation in Parkinson's disease. Nat Neurosci 5:627$628,2002$.

75. Fricker RA, Torres EM, Hume SP et al. The effects of donor stage on the survival and function of embryonic striatal grafts in the adult rat brain. II. Correlation between positron emission tomography and reaching behaviour. Neuroscience 79:711-722, 1997.

76. Kendall L, Rayment D, Aigbirhio F et al. In vivo PET analysis of the status of striatal allografts in the common marmoset. Eur J Neurosci 10:15604, 1998. 
77. Torres EM, Fricker RA, Hume SP et al. Assessment of striatal graft viability in the rat in vivo using a small diameter PET scanner. NeuroReport 6:2017-2021, 1995.

78. Brasted PJ, Watts C, Torres EM et al. Behavioural recovery following striatal transplantation: effects of postoperative training and P-zone volume. Exp Brain Res 128:535-538, 1999.

79. Brasted PJ, Watts C, Torres EM et al. Behavioral recovery after transplantation into a rat model of Huntington's disease: depen- dence on anatomical connectivity and extensive postoperative training. Behav Neurosci 114:431-436, 2000.

80. Bachoud-Levi A, Remy P, Nguyen JP et al. Motor and cognitive improvements in patients with Huntington's disease after neural transplantation. Lancet 356:1975-1979, 2000.

81. Hauser RA, Furtado S, Cimino CR et al. Bilateral human fetal striatal transplantation in Huntington's disease. Neurology 58:687695, 2002. 